\title{
Identification of Polymorphic Forms of Active Pharmaceutical Ingredient in Low-Concentration Dry Powder Formulations by Synchrotron X-Ray Powder Diffraction
}

\author{
Kenji Egusa $^{1} \cdot$ Fumiaki Okazaki $^{1} \cdot$ Joerg Schiewe $^{2} \cdot$ Ulrike Werthmann $^{3}$ • \\ Markus Wolkenhauer ${ }^{2}$
}

Published online: 13 September 2017

(c) The Author(s) 2017. This article is an open access publication

\begin{abstract}
Background The identification of different (pseudo) polymorphs of an active pharmaceutical ingredient in dry powder formulations is of importance during development and entire product lifecycle, e.g., quality control. Whereas determination of polymorphic differences of pure substances is rather easy, in dry powder formulations, it is generally difficult and the difficulties increase particularly, if the substance of interest is present only in low concentrations in the formulation. Such a formulation is Spiriva ${ }^{\circledR}$ inhalation powder (Boehringer Ingelheim), which contains only $0.4 \mathrm{w} / \mathrm{w} \%$ of the active pharmaceutical ingredient tiotropium bromide monohydrate in a matrix of $\alpha$-lactose monohydrate as excipient.

Methods In this study, identification of $0.4 \mathrm{w} / \mathrm{w} \%$ tiotropium bromide in the dry powder formulation was examined by X-ray powder diffraction (XRPD) using a synchrotron radiation source and the results were compared with the conventional laboratory XRPD measurements.

Results The detection limit of tiotropium bromide by the laboratory XRPD was around $2-5 \mathrm{w} / \mathrm{w} \%$, and hence, detection of $0.4 \mathrm{w} / \mathrm{w} \%$ tiotropium bromide was impossible. The synchrotron XRPD was capable to detect significantly
\end{abstract}

Markus Wolkenhauer

markus.wolkenhauer@boehringer-ingelheim.com

1 CMC Department, Kobe Pharma Research Institute, Nippon Boehringer Ingelheim Co., Ltd, Kobe, Japan

2 Respiratory Drug Delivery, Development Germany, Boehringer Ingelheim Pharma GmbH \& Co. KG, Ingelheim, Germany

3 Drug Discovery Sciences, Development Germany, Boehringer Ingelheim Pharma GmbH \& Co. KG, Biberach, Germany lower level of tiotropium bromide by at least an order of magnitude.

Conclusion Four different polymorphic forms of tiotropium bromide present at $0.4 \mathrm{w} / \mathrm{w} \%$ concentration in lactose powder blends were unambiguously identified by the synchrotron XRPD method.

\section{Key Points}

The detection limit of laboratory XRPD was found to be in the range of $2 \mathrm{w} / \%-5 \mathrm{w} / \mathrm{w} \%$ and could be extended by the use of synchrotron based as low as $0.4 \mathrm{w} / \mathrm{w} \%$.

Lower limits could be possible by the use of single photon counting detectors.

\section{Introduction}

Control over the (pseudo)polymorphic forms of the active pharmaceutical ingredient during both development and the entire product lifecycle is essential to ensuring the safety, efficacy and quality of the drug products since differences in the polymorphic forms may have an influence on manufacturability, biopharmaceutical performance, and stability of the drug products $[1,2]$. However, establishing a reliable analytical method for the detection of different polymorphic forms in the presence of pharmaceutical excipients is generally difficult $[3,4]$, particularly in highly-potent drug formulations such as Spiriva ${ }^{\circledR}$ inhalation powder, which contains only $0.4 \mathrm{w} / \mathrm{w} \%$ tiotropium bromide monohydrate as the active pharmaceutical 
ingredient for the therapeutic treatment of chronic obstructive pulmonary disease. Tiotropium bromide can be present as monohydrate, which is the crystal form used for the manufacture of commercial drug products, as well as anhydrate Forms I, II, and III. Commonly used analytical methods such as differential scanning calorimetry [5, 6] and laboratory X-ray powder diffraction (XRPD) [7, 8] are not applicable to the measurement of Spiriva ${ }^{\circledR}$ inhalation powder due to insufficient sensitivity and resolution, along with interference by pharmaceutical excipients. Imaging methods such as Raman microscopy [9, 10] can be used, but only the surface of the test sample can be measured, and, due to the spatial resolution needed [11, 12], measuring a reasonable range of test samples requires a considerable time since a small quantity of micronized crystals of the active pharmaceutical ingredient is scattered in a large volume of pharmaceutical excipient (Fig. 1). Therefore, a more suitable analytical method with required sensitivity and resolution was needed. In this study, synchrotron XRPD [13-16], which has advantages of high sensitivity and high resolution by virtue of highly bright and parallel synchrotron radiation, was examined and compared with laboratory XRPD.

\section{Materials and Methods}

\subsection{Materials}

- Micronized tiotropium bromide monohydrate (Boehringer Ingelheim Pharma GmbH \& Co. KG, Germany).

- Micronized tiotropium bromide anhydrate Form I (Boehringer Ingelheim Pharma GmbH \& Co. KG, Germany).

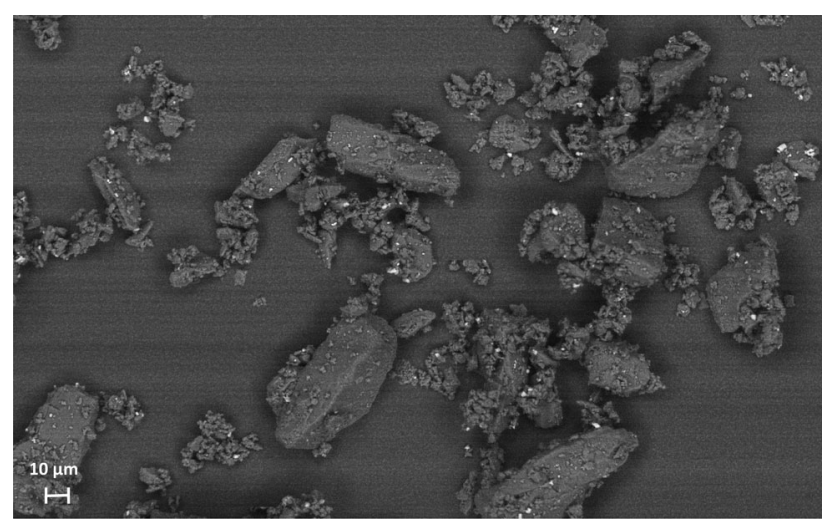

Fig. 1 SEM picture of a lactose powder blend containing $0.4 \mathrm{w} / \mathrm{w} \%$ tiotropium bromide monohydrate in the back-scattering electron mode. The gray-shaded particles are lactose particles, whereas the light particles are tiotropium bromide monohydrate detected by the presence of bromine. SEM scanning electron microscope
- Micronized tiotropium bromide anhydrate Form II (Boehringer Ingelheim Pharma GmbH \& Co. KG, Germany).

- Micronized tiotropium bromide anhydrate Form III (Boehringer Ingelheim Pharma GmbH \& Co. KG, Germany).

- Pharmatose ${ }^{\circledR}$ 200M ( $\alpha$-lactose monohydrate) (DFE Pharma, The Netherlands).

\subsection{Equipment}

- Resodyn LabRAM Acoustic Mixer (Resodyn Acoustic Mixers, Inc., Butte, MT, USA).

- High-performance liquid chromatography/ultra-performance liquid chromatography [HPLC/UPLC; Agilent 1200 SL with diode array detector, Agilent 1200 SL with multiple wavelength detector, Waters Acquity with tunable ultraviolet (UV) detector].

- Glovebox, custom made (Boehringer Ingelheim Pharma GmbH \& Co. KG, Germany).

- Laboratory XRPD: Measurements were carried out using STOE Stadi P with Mythen1K detector (STOE \& Cie $\mathrm{GmbH}$, Germany) by $\mathrm{CuK}_{\alpha 1}$ radiation wavelength $\lambda=1.54 \AA$.

- Synchrotron XRPD: Measurements were carried out using a high-resolution type Debye-Scherrer camera equipped with a curved imaging plate detector at the BL19B2 beamline of the large synchrotron radiation facility 'SPring-8' (Hyogo, Japan) with a wavelength of $1.0 \AA$ A [15].

\subsection{Sample Preparation}

Lactose powder blends containing different polymorphic forms of tiotropium bromide were prepared by weighing $5 \mathrm{~g}$ of Pharmatose ${ }^{\circledR} 200 \mathrm{M}$ and each $0.4 \mathrm{w} / \mathrm{w} \%$ tiotropium bromide polymorph in glass vessels and subsequently mixing. The glass vessels were closed, sealed with Parafilm $^{\circledR}$, and then placed in a Resodyn LabRAM acoustic mixer at $70 \%$ power for $20 \mathrm{~min}$. For the laboratory XRPD measurements only, lactose powder blends containing 1, 2, and $5 \mathrm{w} / \mathrm{w} \%$ of the anhydrous (Form I) and monohydrous tiotropium bromide were prepared. For the anhydrous forms of tiotropium bromide, samples were handled in a glovebox flushed with nitrogen to maintain the relative humidity level below $3 \%$ to ensure that only traces of water were present in the samples.

The blend content uniformity of tiotropium bromide was measured taking ten samples from each lactose powder blend by means of HPLC, obtaining a coefficient of variation of $<4 \%$, indicating uniform mixing.

For the laboratory XRPD measurements, the lactose powder blends were placed in sample pans and slightly 
pressed to ensure a smooth surface, while for the synchrotron XRPD measurements, the lactose powder blends and pure substances of tiotropium bromide as references were filled in Lindemann glass capillaries $(1.0 \mathrm{~mm}$ in diameter).

\subsection{Measurements}

In the laboratory XRPD measurements, tiotropium bromide monohydrate, anhydrate Form I, $\alpha$-lactose monohydrate, and the lactose powder blends containing 1, 2, and $5 \mathrm{w} / \mathrm{w} \%$ monohydrate or anhydrate Form I were investigated. In the synchrotron XRPD measurements, tiotropium bromide monohydrate, anhydrate Form I, anhydrate Form II, anhydrate Form III, $\alpha$-lactose monohydrate, and the lactose powder blends containing $0.4 \mathrm{w} / \mathrm{w} \%$ tiotropium bromide polymorphs were investigated. The pure substances were measured as references to identify the regions where diffraction peaks of the different tiotropium bromide polymorphs appear, with no overlapping peaks originating from $\alpha$-lactose monohydrate. The X-ray exposure time for pure substances was $5 \mathrm{~min}$, which was sufficient for the detection and differentiation of diffraction peaks of pure substances.

However, preliminary experiments revealed that the detection of a small quantity of tiotropium bromide in the presence of overwhelming excipient was not possible by 5 -min X-ray exposure, hence extension of the X-ray exposure time was required. In order to extend the X-ray exposure time, the regions on the imaging plate detector, where peaks from $\alpha$-lactose monohydrate appeared, i.e. 5.15-5.92, 8.22-9.20, and 11.61-12.37 $\AA^{-1}$, were masked by using lead tapes (thickness approximately $1 \mathrm{~mm}$ ) to prevent overexposure and destruction of the imaging plate detector. While omitting the highly intensive diffraction peaks of $\alpha$-lactose monohydrate, diffraction as a result of the small quantity of tiotropium bromide was accumulated and the intensity of diffraction peaks was enhanced by extending the X-ray exposure time. X-ray exposure for $2 \mathrm{~h}$ was appropriate for unambiguous detection of $0.4 \mathrm{w} / \mathrm{w} \%$ tiotropium bromide polymorphs in the lactose powder blends. The effects of radiation damage during an exposure time of $2 \mathrm{~h}$ are considered negligible since pharmaceuticals in their dry solid state are seen as being less prone for such damages [17].

For comparison reasons, the data obtained were transformed from a $2 \theta$ angle to scattering vector q, using Eq. 1: $q=4 \pi / \lambda \sin \theta$

\section{Discussion}

In Fig. 2, the laboratory XRPD patterns of tiotropium bromide monohydrate, and the corresponding 1,2, and $5 \mathrm{w} / \mathrm{w} \%$ lactose powder blends and pure $\alpha$-lactose monohydrate, are displayed. As can be seen, the marker peaks of tiotropium bromide monohydrate $P_{1}=10.51 \AA^{-1}$ and $P_{2}=11.92 \AA^{-1}$ are barely visible at a concentration of $5 \mathrm{w} / \mathrm{w} \%$. At the lower concentrations ( 1 and $2 \mathrm{w} / \mathrm{w} \%$ ), the intensity of these marker peaks is in the range of the noise.

In Fig. 3, the laboratory XRPD patterns of tiotropium bromide anhydrate Form I, and the corresponding 1, 2, and $5 \mathrm{w} / \mathrm{w} \%$ lactose powder blends and pure $\alpha$-lactose monohydrate, are displayed. As for tiotropium bromide
Fig. 2 Laboratory XRPD patterns of tiotropium bromide monohydrate, the corresponding 1,2 and $5 \mathrm{w} / \mathrm{w} \%$ lactose powder blends, and $\alpha$-lactose monohydrate. The black boxes indicate the undisturbed peak positions of tiotropium bromide monohydrate $P_{1}=10.51 \AA^{-1}$ and $P_{2}=11.92 \AA^{-1}$. Intensity was normalized and a factor was added for better visibility. $X R P D \mathrm{X}$-ray powder diffraction

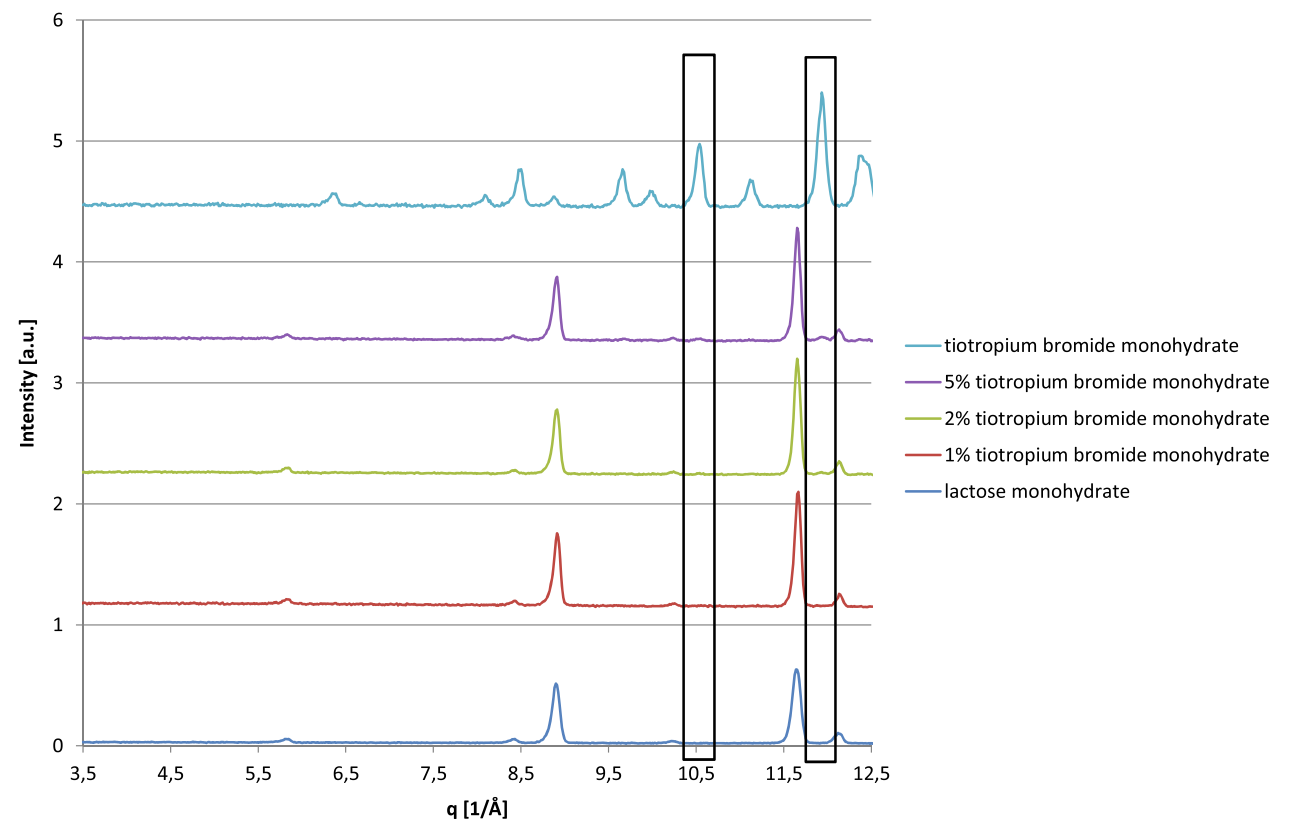


Fig. 3 Laboratory XRPD patterns of tiotropium bromide anhydrate Form I, the corresponding 1, 2 and $5 \mathrm{w} / \mathrm{w} \%$ lactose powder blends, and $\alpha$ lactose monohydrate. The black boxes indicate undisturbed peak positions from tiotropium bromide anhydrate Form I $P_{1}=6.24 \AA^{-1}$,

$P_{2}=9.24 \AA^{-1}$,

$P_{3}=10.00 \AA^{-1}$ and

$P_{4}=11.07 \AA^{-1}$. Intensity was normalized and a factor was added for better visibility. $X R P D \mathrm{X}$-ray powder diffraction
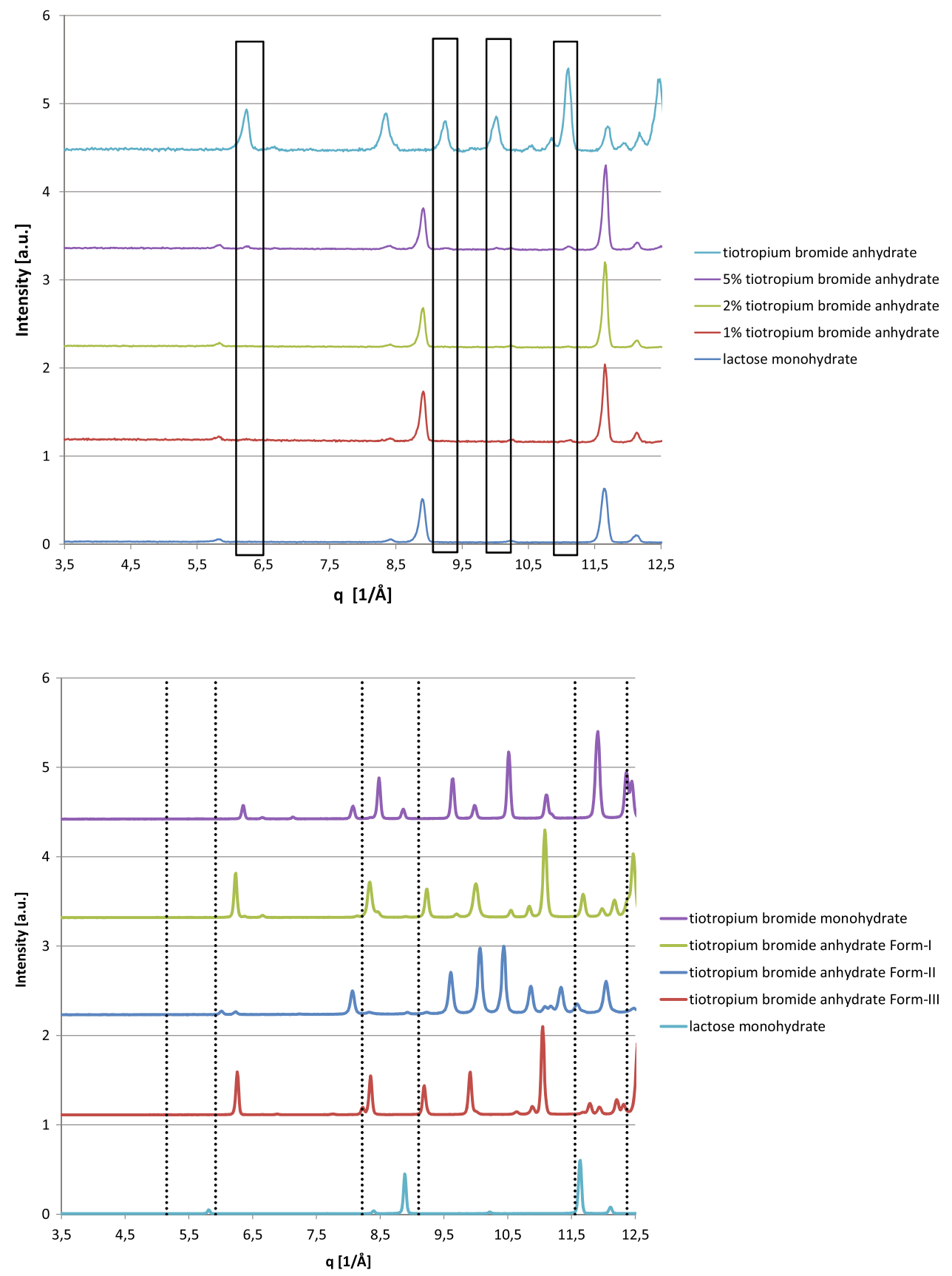

Fig. 4 Synchrotron XRPD patterns of the pure substances: tiotropium bromide monohydrate, tiotropium bromide anhydrate Form I, Form II, and Form III, and $\alpha$ lactose monohydrate (X-ray exposure time: $5 \mathrm{~min}$ ). Black dotted lines denote the areas to be masked. XRPD X-ray powder diffraction monohydrate, the marker peaks of tiotropium anhydrate Form I $P_{1}=6.24 \AA^{-1}, \quad P_{2}=9.24 \AA^{-1}, \quad$ and $P_{3}=11.07 \AA^{-1}$ are barely visible at a concentration of $5 \mathrm{w} / \mathrm{w} \%$. Below a concentration of $5 \mathrm{w} / \mathrm{w} \%$, the intensity of these marker peaks is in the range of the noise. Detection, and thus clear identification below a concentration level of $5 \mathrm{w} / \mathrm{w} \%$, is, in both cases, not possible, and the detection limit is within the range of 2 and $5 \mathrm{w} / \mathrm{w} \%$.

For both monohydrate and anhydrate Form I, laboratory XRPD is not capable of detecting $0.4 \mathrm{w} / \mathrm{w} \%$ tiotropium bromide in lactose powder blends. An increase in X-ray exposure time for the laboratory XRPD would not lower the detection limit since the intensity of these marker peaks is in the range of the noise due to systematic errors. This would prevent the low-intensity marker peaks becoming visible, even at longer measuring times. The use of synchrotron XRPD, with the advantage of its low signal-to-noise ratio, in combination with high-beam intensities, offers the possibility of lowering the detection limit in the desired range.

In Fig. 4, the synchrotron XRPD patterns of the pure substances, i.e. tiotropium bromide monohydrate, anhydrate Form I, anhydrate Form II, anhydrate Form III, and $\alpha$ lactose monohydrate, are displayed. In the regions of 5.92-8.22 $\AA^{-1}$ (region 1) and 9.20-11.61 $\AA^{-1}$ (region 2), 
Table 1 Marker peaks of the different polymorphic forms of tiotropium bromide in regions 1 $\left(5.92-8.22 \AA^{-1}\right)$ and 2 $\left(9.20-11.61 \AA^{-1}\right)$

\begin{tabular}{llllll}
\hline Polymorphic form & Region 1 & \multicolumn{2}{l}{ Region 2 } & & \\
\cline { 3 - 6 } & Peak 1 $\left(\AA^{-1}\right)$ & Peak 1 $\left(\AA^{-1}\right)$ & Peak 2 $\left(\AA^{-1}\right)$ & Peak 3 $\left(\AA^{-1}\right)$ & Peak 4 $\left(\AA^{-1}\right)$ \\
\hline Monohydrate & 6.32 & 9.62 & 9.98 & 10.51 & 11.11 \\
Anhydrate Form I & 6.24 & 9.24 & 10.00 & - & 11.07 \\
Anhydrate Form II & - & 9.61 & 10.07 & 10.44 & 10.86 \\
Anhydrate Form III & 6.26 & - & 9.91 & - & 11.05 \\
\hline
\end{tabular}

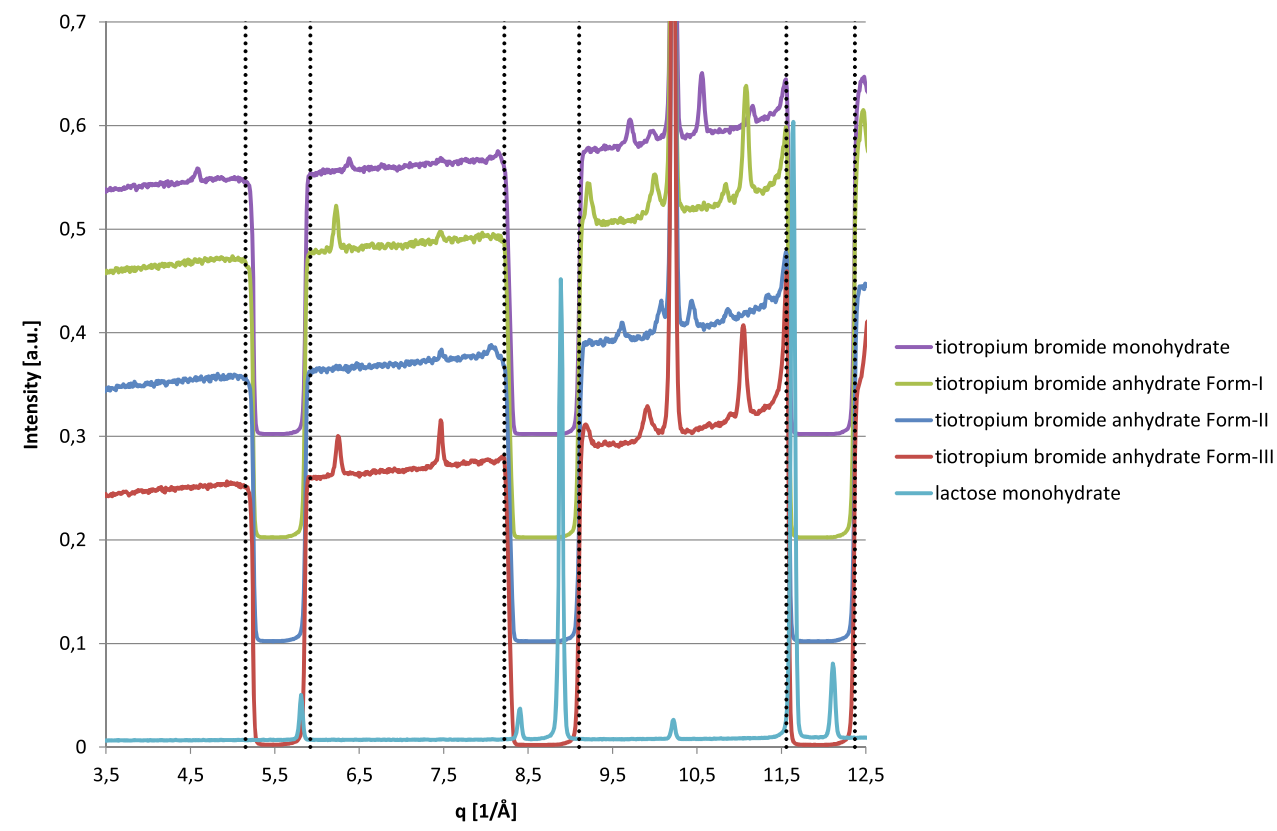

Fig. 5 Synchrotron XRPD patterns of the lactose powder blends containing $0.4 \mathrm{w} / \mathrm{w} \%$ tiotropium bromide anhydrate Form III, anhydrate Form II, anhydrate Form I, and monohydrate (X-ray exposure time $2 \mathrm{~h}$ ). Regions of 5.15-5.92, 8.22-9.20 and 11.61-12.37 $\AA^{-1}$ were masked with lead tapes. For comparison reasons, the

different marker peaks for each polymorphic form of tiotropium bromide can be identified (see Table 1) which are not overlapped by peaks from $\alpha$-lactose monohydrate.

In Fig. 5, synchrotron XRPD patterns of the lactose powder blends containing $0.4 \mathrm{w} / \mathrm{w} \%$ tiotropium monohydrate, anhydrate Form I, anhydrate Form II, and anhydrate Form III are displayed. The regions where intensive peaks from $\alpha$-lactose monohydrate appear are completely masked by lead tapes on the imaging plate detector. Within the unmasked regions, peaks originating from the different polymorphic forms of tiotropium bromide and $\alpha$-lactose monohydrate are visible. The visibility of the diffraction patterns, i.e. angles and intensities, of the marker peaks of tiotropium bromide in the unmasked regions allows for unambiguous identification of all the different polymorphic forms in the lactose powder blend. Thus, the method for polymorphic identification of tiotropium bromide in low concentrations in the dry powder formulation has been established. synchrotron XRPD patterns of $\alpha$-lactose monohydrate (X-ray exposure time: 5 min without masking) are also shown. Black dotted lines denote the masked areas. The large peak in region 2 at $10.21 \AA^{-1}$, visible in all tiotropium blend graphs, is originated by lactose monohydrate. $X R P D \mathrm{X}$-ray powder diffraction

In this method, powdery samples, such as an inhalation powder, can be subjected to measurement by filling a glass capillary only, without any other preparation. Any crystalline substance can be detected, as long as the region where marker diffraction peaks of targeted substance appear without interference by excipients are available. Therefore, it is considered that this method is potentially applicable to any other active pharmaceutical ingredients and dry powder formulations with low drug concentrations.

\section{Conclusions}

The use of synchrotron XRPD enables the detection and identification of different polymorphic forms of tiotropium bromide in low concentrations in dry powder formulations. Whereas the detection limit of laboratory XRPD is in the range of 2-5 w/w\%, synchrotron XRPD allows detection 
and identification of $0.4 \mathrm{w} / \mathrm{w} \%$ tiotropium bromide polymorphs when blended with $\alpha$-lactose monohydrate. Even lower amounts are possibly detectable since the marker peaks, depending on the polymorphic forms, are fairly above the background levels. For example, tiotropium bromide anhydrate Form I and Form III, as well as the monohydrate form, show relatively intense peaks, whereas tiotropium bromide anhydrate Form II peaks are less pronounced. The identification method established by the use of synchrotron XRPD offers the possibility of the assessment of polymorphic changes in the manufacturing process and shelf-life of drug products during both development and the entire product lifecycle. This method is potentially applicable to other drug substances and dry powder formulations with lower drug concentrations. The achievable level of detection may be lower than reported here, depending on the active pharmaceutical ingredient, its polymorphic forms, particle size distribution, domain size and thus pathway of polymorphic conversion thereof, and pharmaceutical composition. Furthermore, the use of single photon-counting detectors could provide an even higher level of resolution, and thus an even lower level of detection.

Acknowledgements Synchrotron XRPD measurements were performed at the beamline BL19B2 of the large synchrotron radiation facility SPring-8 (Hyogo, Japan) with the approval of the Japan Synchrotron Radiation Research Institute (JASRI), proposal numbers 2011B2028, 2012B1838 and 2013B1521.

\section{Compliance with Ethical Standards}

Conflict of interest Markus Wolkenhauer, Kenji Egusa, Jörg Schiewe, Ulrike Werthmann, and Fumiaki Okazaki declare no conflict of interests other than being employed by a company that is the marketing authorization holder for tiotropium-containing products.

Funding No funding was received for this publication.

Open Access This article is distributed under the terms of the Creative Commons Attribution-NonCommercial 4.0 International License (http://creativecommons.org/licenses/by-nc/4.0/), which permits any noncommercial use, distribution, and reproduction in any medium, provided you give appropriate credit to the original author(s) and the source, provide a link to the Creative Commons license, and indicate if changes were made.

\section{References}

1. Hilfiker R. Polymorphism. KG: Wiley-VCH Verlag GmbH \& Co; 2006.
2. Llinàs A, Goodman JM. Polymorph control: past, present and future. Drug Discov Today. 2008;13(5-6):198-210.

3. Sood J, Sapra B, Bhandari S, Jindal M, Tiwary AK. Understanding pharmaceutical polymorphic transformations. I: influence of process variables and storage conditions. Ther Deliv. 2014;5(10):1123-42.

4. Xie Y, Tao W, Morrison H, Chiu R, Jona J, Fang J, et al. Quantitative determination of solid-state forms of a pharmaceutical development compound in drug substance and tablets. Int $\mathbf{J}$ Pharm. 2008;362(1-2):29-36.

5. Grisedale L, Jamieson M, Belton PS, Barker SA, Craig DQM. The effect of milling on the physical structure and properties of salbutamol sulphate: a thermal, spectroscopic and water vapour sorption study. J Pharm Sci. 2011;100:3114-29.

6. Kiong Ng W, Kwek JW, Yuen A, Tan CL, Tan R. Effect of milling on DSC thermogram of excipient adipic acid. AAPS Pharm Sci Tech. 2010;11(1):159-67.

7. Bezzon VDN, Antonio S, Paiva-Santos CO. Limits of visual detection for finasteride polymorphs in prepared binary mixtures: analysis by X-ray powder diffraction. J Pharm Sci. 2014;103(11):3567-75.

8. Davidovich M, Mueller R, Raghavan K, Ranadive S, Vitez I, Sarsfield B. The role of powder X-ray diffraction as a powerful tool in characterization of various hydrates of drug substance. Am Pharm Rev. 2001;4:53-60.

9. Paudel A, Raijada D, Rantanen J. Raman spectroscopy in pharmaceutical product. Adv Drug Deliv Rev. 2015;89:3-20.

10. Wang H, Boraey MA, Williams L, Lechuga-Ballesteros D, Vehring R. Low-frequency shift dispersive Raman spectroscopy for the analysis of respirable dosage. Int $\mathrm{J}$ Pharm. 2014;469(1):197-205.

11. Adar F, Mamedov S, Whitely A. Limits of spatial resolution of a Raman microscope. Microsci Microanal. 2005;11(Suppl 2):728-9.

12. Dračínský M, Procházková E, Kessler J, Šebestík J, Matějka P, Bour P. Resolution of organic polymorphic crystals by Raman spectroscopy. J Phys Chem B. 2013;117(24):7297-307.

13. Masuda K, Ishige T, Yamada H, Fujii K, Uekusa H, Miura K, et al. Study of the pseudo-crystalline transformation from Form I to Form II of thiamine hydrochloride (vitamin B1). Chem Pharm Bull. 2011;59(1):57-62.

14. Yamada H, Masuda K, Ishige T, Fujii K, Uekusa H, Miura K, et al. Potential of synchrotron X-ray powder diffractometry for detection and quantification of small amounts of crystalline drug substances in pharmaceutical tablets. J Pharm Biomed Anal. 2011;56(2):448-53.

15. Takata M, Nishibori E, Kato K, Kubota Y, Kuroiwa Y, Sakata M. High resolution Debye-Scherrer camera installed at SPring-8. Adv X-Ray Anal. 2002;45:377-84.

16. Stephens PW. What's in your pill? What about theirs? Modern $\mathrm{X}$-ray analysis in the pharmaceutical industry using synchrotron radiation. Am Pharm Rev. 2002;5:62-6.

17. Silindir M, Ozer Y. The effect of radiation on a variety of pharmaceuticals and materials containing polymers. PDA J Pharm Sci Technol. 2012;66(2):184-99. 